\title{
Imperfeições no mercado de crédito e racionamento \\ de crédito: uma análise para o setor informal no Brasil
}

\section{Palavras-chave \\ informalidade, informação assimétrica, riqueza, racionamento de crédito. \\ Classificação JEL \\ J24, L26, O17. \\ Keywords \\ informality, asymmetric information, wealth, credit constraint.}

\section{JEL Classification}

J24, L26, O17.

\begin{abstract}
Resumo
$\mathrm{O}$ artigo analisa a existência de racionamento de crédito dentro do setor informal urbano, pequenos proprietários, no Brasil. Sob restrição de crédito, o investimento ocorrem um nível subótimo ou até mesmo não se realiza. Para testar se a restrição de crédito é ativa, parte-se da relação entre riqueza e decisão de investimento. Quanto mais forte e positiva a relação entre investimento e riqueza, mais ativa será a restrição de crédito. Utilizando dados da ECINF (Pesquisa de Economia Informal Urbana), são estimadas equações de decisão sobre investimento e seu valor, com controles das características individuais de empreendedores e unidades econômicas.
\end{abstract}

\author{
Flávia Chein* \\ Uirá Mendes Vieira da Silva**
}

\section{Abstract}

This paper aims to analyze the limiting of credit considering the informal industry at Brazil's urban areas. The goal is to acknowledge if informal business owners rely on restrictive access into credit market. Considering the credit constraint, the investment could be done in a suboptimal level or yet not succeed. In order to test whether the credit constraint is active in between entrepreneurs from informal sector, it is assumed the relationship between wealth and individual choices, specifically, wealth and the decision-making regarding to investments. Then, the higher is the positive relation between investment and wealth; more active will be the credit constraint. Based on ECINF (Urban Informal Economy's Research), were estimated decision equations over investment and its value, controlling by distinctive characteristics of entrepreneurs and economic units. The results indicate the existence of active credit constraint in informal industry at Brazilian urban areas. 


\section{1_Introdução}

De acordo com a teoria econômica, havendo mercados de crédito perfeitos, todo e qualquer investimento que fosse capaz de cobrir seus custos seria efetuado; mas, na presença de imperfeições do mercado de crédito, os agentes passariam a depender também da sua dotação inicial. Dessa forma, países que apresentem nível similar de desenvolvimento, porém com distribuições iniciais de riqueza diferentes, estariam sujeitos a alcançar níveis de desenvolvimento diferentes no longo prazo, podendo haver múltiplos equilíbrios (Galor; Zeira, 1993). O funcionamento do mercado de crédito pode ser uma chave para se entender a desigualdade de renda, a pobreza e a informalidade.

Diante de um mercado imperfeito, se um empreendedor necessita de determinada quantia para realizar um investimento e não possui todo o valor necessário, então uma forma de obter esse dinheiro seria por meio de crédito. Contudo, em mercados de crédito imperfeitos, em razão da existência de informação assimétrica, os emprestadores incorreriam em elevados custos para monitorar os agentes e garantir que esses escolhessem os investimentos com maior probabilidade de garantir o pagamento dos empréstimos (Stiglitz; Weiss, 1981).

Em um contexto de existência de informação assimétrica, os emprestadores estão sujeitos a situações em que não receberão o dinheiro, seja por uma situação involuntária, seja por uma situação voluntária. No primeiro caso, ainda que tenha a intenção de pagar o empréstimo, o agente pode estar sujeito a riscos inerentes a qualquer tipo de atividade e, portanto, ficar inabilitado de saldar seus débitos. Por outro lado, ambientes institucionais cujos sistemas legais são frouxos podem funcionar também como incentivos; para que haja risco moral, os agentes têm condições de saldar o empréstimo, mas, por causa da falta de punições severas, optam voluntariamente pelo calote.
Diante da existência de informação assimétrica e risco moral, os emprestadores escolhem por requerer garantias, exigindo que os agentes apresentem colaterais (garantias) para que possam ter acesso ao crédito; contudo, isso faz com que o crédito se torne uma opção inviável para os mais pobres, já que esses ou não possuem colateral, ou o colateral não atende às exigências. Dessa forma, a exigência de colateral, assim como o risco moral existente nas transações, pode levar a uma situação de restrição de crédito. Em um mercado perfeito, a demanda e a oferta se igualariam, fornecendo a taxa de juros no equilíbrio, mas, diante de imperfeições, haveria uma demanda reprimida, que, mesmo disposta a pagar taxas de juros mais altas, não seria atendida (Jaffee; Russel, 1976; Stiglitz; Weiss, 1981, 1986).

Ao se observar o ambiente no qual estão inseridas as micros e pequenas empresas brasileiras, o que se verifica é exatamente a falta de capital inicial por parte dos pequenos empreendedores; assim, a única opção desses, caso queiram investir em projetos com alta produtividade, é recorrer ao mercado de crédito. Mas, se levarmos em consideração a existência de possíveis restrições de crédito na economia, então esses empreendedores não conseguem obter a quantidade desejada de crédito, uma vez que o prêmio de risco exigido pode ser elevado ou a quantia emprestada pode ser limitada, assim como não são capazes de oferecer ou não possuem colateral (garantias) que atendam às exigências dos emprestadores.

Dessa forma, os pequenos empreendedores ver-se-ão impedidos de investir nos projetos mais eficientes e que lhes deem o maior retorno (Banerjee; Newman, 1993; Aghion; Bolton, 1997; Galor; Zeira, 1989). De acordo com a literatura econômica, se indivíduos pobres e sem acesso a crédito não possuem condições de investir de forma a otimizar seu retorno, então a eficiência produtiva da economia será re- 
duzida, o que pode criar "armadilhas de pobreza", em que o ciclo de baixa renda é transmitido às gerações futuras (Banerjee, 2006).

Valendo-se da base de dados da ECINF, e conforme a metodologia adotada por Assunção e Chein (2007) e Assunção e Alves (2007), busca-se estabelecer relação entre a riqueza inicial dos indivíduos e as suas decisões de investimentos. As possíveis restrições de crédito serão medidas de forma indireta por meio da correlação entre a riqueza dos indivíduos e as suas escolhas. Diante de restrições de crédito, espera-se que as escolhas das famílias sejam uma função da sua riqueza individual, já que, caso não houvesse restrições ativas na economia, as escolhas dos indivíduos dar-se-iam por meio de uma comparação entre custos e benefícios.

No capítulo 2, será feita uma revisão da literatura teórica e empírica sobre os fatores que condicionam o racionamento de crédito, procurando demonstrar como as imperfeições no mercado de crédito podem conduzir a um equilíbrio competitivo em que há demanda por crédito reprimida. No terceiro capítulo, será apresentada a base de dados e o estabelecimento de uma correlação entre riqueza e decisão de investimento. No capítulo 4, serão apresentados e discutidos os resultados. Por fim, no capítulo 5, serão feitas as considerações finais.

\section{2_Revisão da literatura}

Grande parte da discussão sobre acesso ao crédito é permeada por questões relativas à informação e à incerteza. $\mathrm{O}$ desconhecimento do tipo do agente tomador do empréstimo e da sua capacidade de saldar o empréstimo ou não, diante do fracasso ou do sucesso de seu empreendimento, torna os mercados de crédito sujeitos a incertezas, o que, de certa forma, diferencia esse mercado dos demais. Não é possível se determinar o equilíbrio entre a demanda e a oferta por crédito, e este pode ocorrer em um ponto em que ainda haja excesso de demanda por crédito, já que não se pode probabilisticamente determinar quando uma promessa será cumprida ou não (Jaffee; Stiglitz, 1990). Em mercados imperfeitos, a taxa de juros, isto é, o "preço" que iguala a oferta à demanda por crédito, serviria apenas para indicar o que o indivíduo se comprometeu a pagar, sem dizer se isso realmente ocorrerá. Com isso, não seria possível eliminar o excesso de demanda e obter o ponto de equilíbrio ótimo entre a oferta e a demanda através da taxa de juros. Logo, a resposta dos emprestadores à incerteza se traduz em aversão ao risco. $\mathrm{O}$ racionamento de crédito é, portanto, resultado da aversão dos emprestadores ao risco de inadimplência.

Vários autores, entre os quais se encontram Jaffee e Russel (1976), Stiglitz e Weiss (1981), Galor e Zeira (1989), Aghion e Bolton (1997) e Banerjee (2001), têm se dedicado a estudar o funcionamento do mercado de crédito e suas imperfeições sob diferentes óticas, que vão desde a escolha da taxa de juros e nível de oferta de crédito pelos bancos até os efeitos de tais imperfeições sobre as escolhas ótimas de investimento e os níveis de desigualdade entre os indivíduos.

Cabe destacar o trabalho seminal de Stiglitz e Weiss (1981), em que os autores analisam os efeitos do aumento da taxa de juros por meio do problema da seleção adversa e do risco moral. A diferença nesse modelo é que o racionamento de crédito se dá mediante a exclusão de potenciais tomadores; nem todos esses, dispostos a tomar empréstimos, conseguirão fazê-lo. No mercado de crédito apresentado por eles, conforme a taxa de juros é elevada, os potenciais tomadores de crédito que apresentam maiores probabilidades de pagarem o empréstimo desistem de tomar emprestado, restando os tomadores com maior probabilidade de escolher projetos mais arriscados.

Há ainda outro efeito decorrente do aumento das taxas de juros que ocorre sobre o comportamento dos agentes to- 
madores que se aplicam na obtenção de crédito: elevações na taxa de juros fazem com que os tomadores tendam a escolher projetos de maior retorno, mas que têm menor probabilidade de sucesso e, portanto, menor probabilidade de pagamento do empréstimo. Desse modo, os bancos também vão preferir emprestar a taxas de juros menores e restringir o crédito; nem todos os agentes que se submeterem a um pedido de crédito serão atendidos, mesmo se dispostos a pagarem taxas de juros mais elevadas; no modelo de Jaffee e Russel (1976), a restrição se dá porque nem todos os tomadores terão acesso à quantidade de crédito que desejam.

De outro lado, autores como Bester (1985) e Besanko e Thakor (1987; 1987b) advogam que os contratos de crédito não são regidos apenas pela taxa de juros cobrada; um fator que deve ser levado em consideração quando se analisam restrições de crédito é a exigência de garantias ou colaterais. Há autores que ressaltam que o colateral pode ser usado para separar os potenciais tomadores de crédito, de acordo com o seu risco individual, desde que haja a possibilidade de oferecer diferentes contratos, de modo que o requerimento de colateral atuaria como mecanismo de seleção. Os tomadores que escolhem projetos com maior probabilidade de sucesso estão mais dispostos a aceitar maiores exigências de colateral, enquanto os que tendem a escolher projetos de maior risco preferem taxas de juros menores e menos requerimento de colateral. Dessa forma, no equilíbrio não haveria restrição de crédito.

Mas há argumentos que se contrapõem a essa ideia $\mathrm{e}$ defendem que, mesmo diante de um conjunto de contratos em que haja requerimentos de diversos níveis de colateral, ainda assim, poderia haver racionamento de crédito. Isso aconteceria em razão de nem todos os indivíduos disporem da mesma quantidade de colateral para oferecer; essa dissimilaridade entre os agentes gera efeito de seleção adversa, ou seja, indivíduos mais ricos e com maior colateral para oferecer vão preferir se candidatar a contratos cuja exigência de colateral seja menor. Haveria ainda um problema de risco moral: o banco, para garantir que o tomador realmente estaria dizendo a verdade e que o colateral oferecido realmente seria compatível com a riqueza deste, teria que monitorar o agente e obter informações a seu respeito (Stiglitz; Weiss, 1986).

A literatura econômica sobre o racionamento de crédito também investigou empiricamente os efeitos desse, avaliando os possíveis impactos das restrições de crédito. Rajan e Zingales (1998), por exemplo, estudaram os impactos do setor financeiro sobre o setor industrial utilizando uma base de dados com amostras dos setores industriais, financeiros e do PIB desses 41 países entre 1980 e 1990. Os resultados encontrados pelos autores corroboram a hipótese de que há correlação entre crescimento e desenvolvimento do setor financeiro, e as estimativas sugerem que o impacto do desenvolvimento financeiro é maior sobre as pequenas empresas, enquanto o efeito econômico de menores custos de financiamento demonstrou ser maior sobre o número de empresas do que sobre o tamanho médio das firmas.

Já os trabalhos de Jacoby (1994) e Paulson e Townsend (2004) apontam para os efeitos das restrições de crédito sobre as escolhas dos indivíduos. Enquanto Jacoby (1994) analisa os efeitos de restrições de crédito sobre o progresso de crianças do sistema escolar primário do Peru, Paulson e Townsend (2004) focam nos impactos do racionamento de crédito sobre os pequenos empreendedores, que muitas vezes dispõem de pouco ou nenhum recurso para investir e que, na maioria dos casos, não possuem nenhuma forma de colateral ou garantia para ter acesso ao crédito e geram perda de produtividade e eficiência. Os resultados sugerem que há correlação entre riqueza e empreendedorismo, até mesmo quando há separação por nível educacional. Da mesma forma, quando eles mantêm fixo o talento (cuja proxy é a educação formal), que, 
por sua vez, é pressuposto estar correlacionado com a habilidade "gerencial" do empreendedor, verifica-se que, conforme a riqueza individual aumenta, cai o percentual de empreendedores afetados por restrições de crédito.

No Brasil, a literatura empírica sobre racionamento de crédito é menos prolífica, mas há trabalhos sobre o tema. Um desses estudos foi realizado por Assunção e Alves (2007) e avalia o impacto de restrições de crédito sobre as decisões intrafamiliares, tais como dedicação do chefe e do cônjuge à atividade empresarial, educação das crianças e trabalho infantil. $\mathrm{O}$ estudo utiliza dados da Pesquisa Nacional por Amostra de Domicílios (PNAD) para os anos de 1981 a 2001 e tem por base a mesma hipótese adotada por Paulson e Townsend (2004), de que, na presença de restrições de crédito, a riqueza individual é correlacionada com as decisões de investimento, seja na atividade profissional, seja na educação dos filhos. Os resultados encontrados demonstram que há correlação positiva entre riqueza e probabilidade de o chefe de família ou de o cônjuge ser empresário na presença de restrição de crédito. A mesma correlação é verificada entre a riqueza e a probabilidade de as crianças terem número de anos de estudo igual ou superior à média de acordo com a idade, ano e região. Ademais, verificou-se que há correlação negativa entre riqueza e probabilidade de os filhos trabalharem diante da restrição de crédito, indicando a importância dessa nas decisões de investimento intrafamiliares.

Outra evidência sobre o mercado de crédito brasileiro encontra-se em Assunção e Chein (2007), que serve de base metodológica para o presente trabalho e analisa os efeitos de restrições de crédito sobre as populações rurais no Brasil, utilizando dados dos Censos Demográficos de 1991 e 2000. Os autores estimam o efeito da riqueza individual sobre a educação infantil e sobre a probabilidade de o chefe de família ser um empregador, demonstrando haver evidências de que as restrições de crédito estão ativas no país como um todo, mas variando de região para região. Os resultados são semelhantes aos encontrados por Assunção e Alves (2007) e reforçam as evidências sobre a restrição de crédito ativa para decisões familiares no Brasil.

Por fim, no que tange a evidências sobre imperfeições no mercado de crédito brasileiro, Coelho et al. (2010) apontam que a extensão da oferta de crédito consignado, instituída por lei federal em 2003, causou redução na taxa de juros e aumento no volume de crédito pessoal. Os autores concluem que o empréstimo em folha de pagamento é um instrumento de colaterização recente que apresenta custos de recuperação mais baixos, dado que a garantia é o dinheiro, ou seja, o ativo mais líquido no Brasil.

\section{3_Base de dados e metodologia}

\section{1_Racionamento de crédito e investimento}

A ausência de dados é um dos fatores que prejudica a mensuração do racionamento de crédito. As modalidades de crédito presentes no dia a dia são inúmeras, seja essas de fontes formais, seja de fontes informais, tais como compras a prazo, cheque pré-datado, compra fiado. Há ainda o problema de que, muitas vezes, uma modalidade de crédito é utilizada para financiar atividades diversas daquela para qual foi usada, solução por vezes utilizada pelos pequenos empreendedores para financiar suas atividades produtivas. E, quando se considera o crédito formal, percebe-se que um grande obstáculo para os pequenos empreendedores é a exigência de garantias reais por parte das instituições financeiras.

De acordo com O Financiamento das Micro e Pequenas Empresas (MPEs) paulistas, levantamento do Sebrae-SP realizado entre março e maio de 2009, com cerca de $300 \mathrm{mi}$ cros e pequenas empresas paulistas, as principais fontes 
de financiamento da atividade produtiva utilizadas eram: o pagamento de fornecedores a prazo, o cheque especial, o cartão de crédito e o cheque pré-datado. Das empresas que se aplicaram para a obtenção de crédito, os principais motivos para a não concessão de crédito foram: a falta de documentos, o fato de estarem registradas no CADIN (Cadastro Informativo de Créditos não Quitados do Setor Público Federal) e/ou na Serasa, a falta de recursos próprios e a falta de garantias reais. Entre as empresas que desejavam empréstimos bancários, destacam-se o desejo de utilizar esses empréstimos para pagar fornecedores e/ou comprar mercadorias, comprar máquinas e equipamentos, pagar dívidas e financiar o capital de giro.

Levando-se em conta a dificuldade na obtenção de dados acerca das condições reais de crédito existentes na economia, a alternativa aqui utilizada para verificar a existência de racionamento de crédito é o emprego de uma estratégia indireta baseada em Evans e Jovanovic (1989) e implementada por Assunção e Chein (2007) e Assunção e Alves (2007), que consiste em abordar o problema do racionamento de crédito através da verificação da correlação entre riqueza e escolhas individuais. A ideia por trás dessa estratégia é que, perante restrições de crédito, as decisões dos indivíduos serão influenciadas pela sua dotação inicial.

Conforme explicitado anteriormente, mercados de crédito imperfeitos impedem que os indivíduos que não dispõem de ativos suficientes financiem seus projetos, fazendo com que o montante investido seja abaixo do nível ótimo ou até mesmo com que não haja investimento, o que acaba acarretando perda de produtividade e eficiência econômica e pode até ser apontado como um dos elementos que contribuem para um ciclo "vicioso" permanente de pobreza que se perpetua ao longo do tempo.

Serão estimados dois modelos; em um primeiro momento, um modelo probit que avalia o impacto da riqueza individual sobre a decisão de investir dos proprietários do setor informal em áreas urbanas do Brasil.Em um segundo momento, será estimada uma equação pelo método de mínimos quadrados ordinários (MQO) para calcular os efeitos da riqueza dos indivíduos sobre o valor do investimento realizado.

As escolhas dos indivíduos tanto no modelo probit quanto no método de mínimos quadrados podem ser representados por meio da equação do tipo:

$$
E\left(\theta_{i}, a_{i}\right)=\alpha a_{i}+\beta X_{i}+e_{i}
$$

Tal qual como em Assunção e Chein (2007), a variável $E$ representa as escolhas dos indivíduos, e as escolhas desses dependem das características específicas de cada indivíduo $(\theta)$ e da dotação inicial de riqueza desses $(a)$. O objetivo de tal modelo é verificar o impacto da dotação inicial dos indivíduos sobre suas escolhas, considerando os fatores desses indivíduos que são observáveis $(X)$ e que são não observáveis (e).

\subsection{1_Modelo probit}

Seguindo a especificação adotada por Assunção e Alves (2007), o modelo probit consistirá na estimação da ocorrência ou não de investimento condicionada à riqueza individual dos proprietários do setor informal, considerando ainda as características específicas desses e do empreendimento. A variável que representa as escolhas dos indivíduos será igual a zero, caso o indivíduo selecionado da amostra tenha escolhido não investir, e a 1, caso esse indivíduo tenha escolhido realizar algum investimento e/ ou aquisição. A especificação é dada por:

$$
P\left(E_{i}=1 \mid a_{i}, x_{i}\right)=F\left(\alpha a_{i}+\beta X_{i}\right)
$$


A função $F$ segue uma distribuição normal padronizada, e a variável $E_{i}$ representa as escolhas dos indivíduos, que são, no caso, a decisão do proprietário de investir ou não investir. Diferente dos modelos lineares, não é possível estimar a probabilidade de que o investimento ocorra por meio de MQO; isso acontece pelo fato de o termo de erro $e_{i}$, observado na equação 1, ser heterocedástico. A estimação é realizada, então, por meio do método de máxima verossimilhança, que gera parâmetros consistentes e assintoticamente eficientes.

Espera-se que, mediante a variável que representa a proxy de riqueza individual dos proprietários, seja possível mensurar a existência de restrições de crédito, levando-se em consideração as características de cada indivíduo i, tais como idade, sexo, nível de instrução, número de horas trabalhadas, posição na ocupação, além das características do empreendimento.

\subsection{2_MQO}

A aferição empírica do racionamento de crédito por meio do método de mínimos quadrados ordinários (MQO) se baseia em Assunção e Chein (2007). Assim como no modelo probit, a estimação consiste em uma regressão de uma equação cuja variável dependente representa as escolhas dos indivíduos, indivíduos esses que possuem características específicas $(\theta)$ e uma dotação inicial $(a)$ de riqueza. O objetivo deste modelo é verificar o impacto da dotação inicial dos indivíduos sobre suas escolhas, considerando os fatores de tais indivíduos que são observáveis $(X)$ e que são não observáveis (e).

A diferença é que a variável dependente nesse caso é contínua, o que permite estimar os efeitos da riqueza individual sobre as decisões dos indivíduos através de MQO. As decisões dos proprietários são representadas pelo logaritmo natural do valor dos investimentos e/ou aquisições realizadas pelos trabalhadores por conta própria e empre- gadores com até cinco empregados no período referente aos 12 meses anteriores à pesquisa. A equação a ser estimada considera as características de cada indivíduo i e as características do negócio:

$L n($ valor do investimento $)=\alpha$ riqueza $+\beta X_{i}+e_{i}$ (3)

Espera-se que, quanto maior a riqueza do indivíduo, menor seja o efeito do racionamento de crédito sobre as decisões desse, visto que o indivíduo é capaz de financiar os seus projetos dentro do nível ótimo por meio de recursos próprios.

\section{2_Base de dados}

A base de dados utilizada será a da pesquisa Economia Informal Urbana (ECINF) realizada pelo Instituto Brasileiro de Geografia e Estatística, nos anos 2003, em parceria com o Sebrae. A ECINF procura investigar as características de funcionamento das unidades produtivas que não são captadas ou são captadas apenas parcialmente pelas demais fontes estatísticas disponíveis e que se encontram no setor informal da economia. Não há definição exata de informalidade, já que a economia informal abrange ampla gama de trabalhadores, empresas e empreendedores. Mas, seguindo determinações da Organização Internacional do Trabalho (OIT), a ECINF define o setor informal como aquele que abrange todas as unidades econômicas que sejam propriedades de trabalhadores por conta própria ou de empregadores com no máximo cinco empregados, sejam as atividades exercidas por esses proprietários as atividades principais ou secundárias. Delimitam-se as unidades econômicas que fazem parte do setor informal como aquelas que não fazem parte do setor agrícola e cujo objetivo é a produção voltada para a geração de emprego e renda para as pessoas envolvidas, excluindo-se as unidades que 
produzem apenas para o próprio consumo. Essas unidades são caracterizadas por produzirem em baixa escala, baixo nível de organização e por haver quase nenhuma separação entre capital e trabalho, conquanto fatores de produção. Está excluída também da pesquisa a chamada "população de rua".

Os setores urbanos foram estratificados na amostra probabilística de domicílios inicialmente por sua condição geográfica; em um segundo momento, houve um processo de estratificação das unidades primárias dentro de cada estrato geográfico, que considerou a renda dos indivíduos de forma a incluir na amostra os proprietários do setor informal das mais diversas classes de renda. O tamanho da amostra de cada área de pesquisa utilizou como variável de dimensionamento o total de proprietários do setor informal, com erro de amostragem estimado em $5 \%$, com exceção do Nordeste, que foi de $6 \%$.

Cabe ressaltar que a abrangência da pesquisa é nacional, englobando as áreas urbanas de todas as Unidades da Federação.A amostra de proprietários do setor informal em áreas urbanas do Brasil contida na ECINF possui 48.813 observações, sendo que, para a estimação do modelo probit, serão consideradas todas essas observações. Mas, quando for estimado, o modelo de MQO interessará especificamente a amostra dos proprietários que possuem equipamentos, uma vez que, no questionário da ECINF, apenas esses proprietários responderam se realizaram algum investimento ou alguma aquisição nos 12 meses anteriores à pesquisa, sendo, portanto, tais proprietários a parte da amostra ECINF que contém os valores dos investimentos realizados.

\section{3_Análise descritiva da base de dados}

Quando se visualiza o universo da população de proprietários do setor informal em áreas urbanas do Brasil descrito na amostra de proprietários da base de dados da ECINF 2003 (Tabela 1), é possível perceber que é predominante a concentração de proprietários na região Sudeste (45\%). A região Nordeste responde por $26 \%$ da concentração de proprietários, enquanto a região Sul responde por 15\% dessa. As regiões Norte e Centro-Oeste são as com menor participação de proprietários do setor informal em áreas urbanas do Brasil, 7\% e 6\%, respectivamente.

Tabela 1_Participação no setor informal em áreas urbanas por região - Brasil, 2003

\begin{tabular}{|c|c|c|}
\hline Regiões & $\begin{array}{l}\text { Proprietários } \\
\text { Freq. }\end{array}$ & $\%$ \\
\hline Centro-Oeste & 669.685 & 6,36 \\
\hline Nordeste & 2.763 .987 & 26,26 \\
\hline Norte & 763.092 & 7,25 \\
\hline Sudeste & 4.760 .679 & 45,23 \\
\hline Sul & 1.568 .631 & 14,90 \\
\hline Brasil & 10.526 .074 & 100,00 \\
\hline
\end{tabular}

Fonte: Elaboração própria com base em dados extraídos da ECINF 2003.

É expressiva a presença de trabalhadores por conta própria em relação aos empregadores (Gráfico 1). A população de trabalhadores por conta própria contida na amostra corresponde a $87 \%$ do total de proprietários, ao passo que os empregadores correspondem a $13 \%$. É predominante também a participação dos homens no setor informal em áreas urbanas do Brasil; os proprietários do sexo masculino correspondem a $67 \%$ da população de proprietários contidos na amostra da ECINF, enquanto as mulheres representam $33 \%$ dessa população (Gráfico 2).

A maior parte das atividades desenvolvidas pelos proprietários localizava-se nos ramos de comércio e reparação (36\%), construção civil (19,1\%) e indústria de transformação e extrativa (11\%), conforme pode ser visto no Gráfico 3. Apesar de a maior parte da população de proprietários estar concentrada nas atividades de comércio e reparação, observa-se que há uma diferença quando se toma separadas 
Gráfico 1_Distribuição de trabalhadores por conta própria e empregadores Brasil, nov./2003

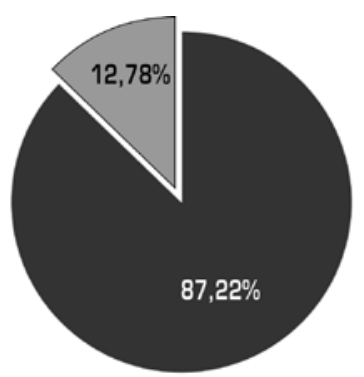

Conta própria $\square$ Empregador
Gráfico 2_Distribuição por sexo dos proprietários -

Brasil, nov./2003

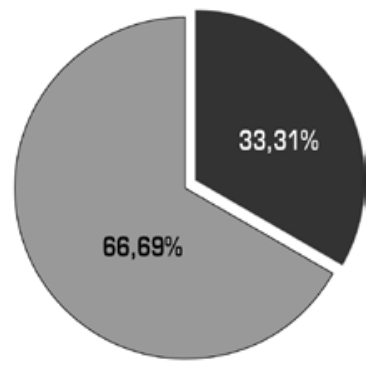

- Feminino $\square$ Masculino
Fonte: Elaboração própria com base em dados extraídos da ECINF, 2003. a participação de empregadores e trabalhadores por conta própria nesta e a no ramo de construção civil. Em 2003, da população de empregadores do setor informal em áreas urbanas do Brasil, 43\% atuavam em atividades de comércio e reparação, ao passo que os empregadores atuantes no ramo da construção civil representavam $13 \%$. Por sua vez, quando se toma a população de trabalhadores por conta própria, observa-se que o ramo de comércio e reparação correspondia pela ocupação de $36 \%$ dessa população, ao passo que o percentual de conta própria atuante no ramo da construção civil era de $20 \%$ da população de trabalhadores por conta própria.

A população de proprietários da amostra da ECINF, segundo as declarações de raça ou cor, é majoritariamente

Gráfico 3_Distribuição dos proprietários por grupo de atividade - Brasil, 2003

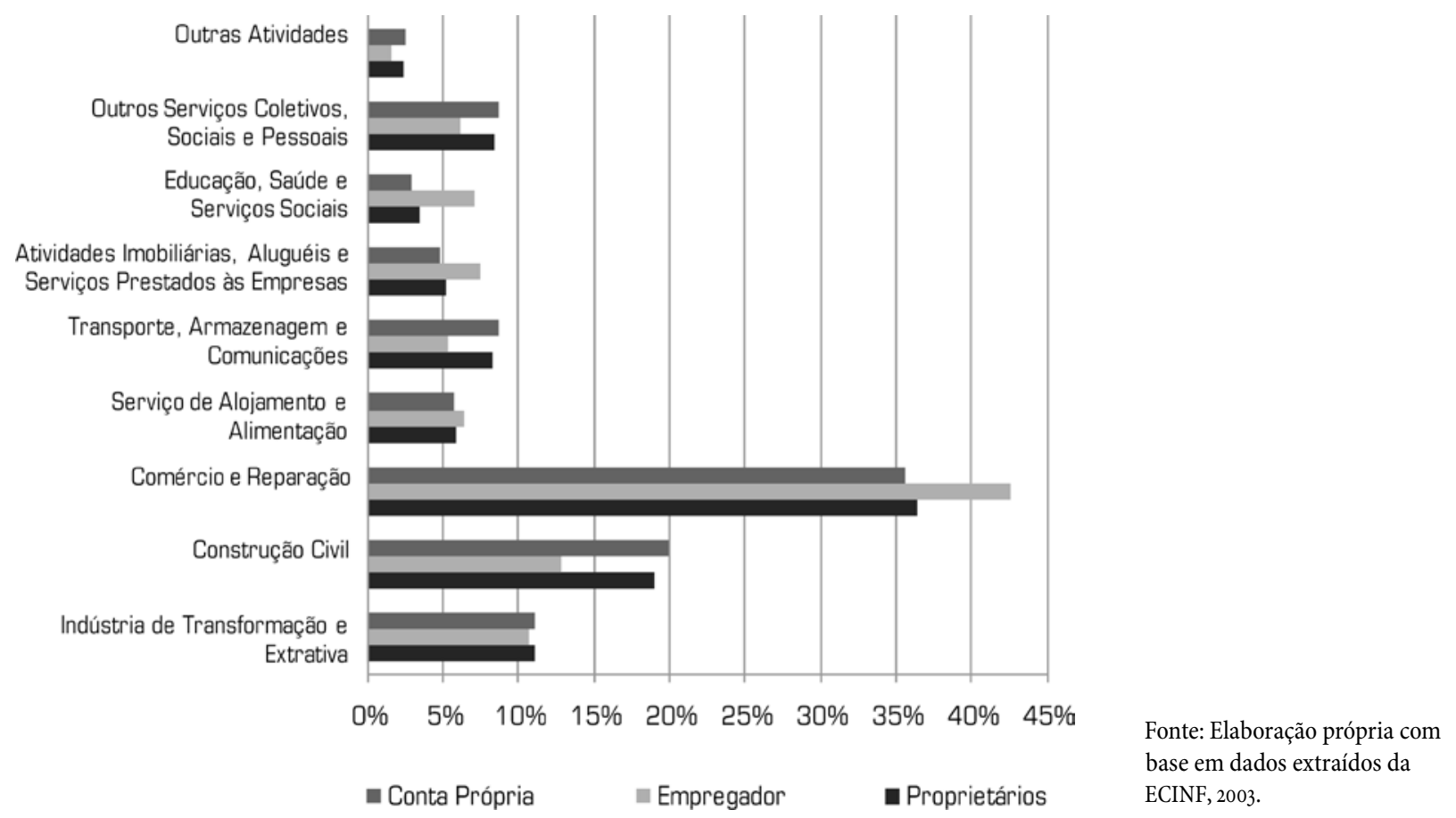


branca (53\%), enquanto os que se declararam pardos representaram $40 \%$ da população de proprietários. Já os indivíduos que se declararam pretos representaram $6 \%$, enquanto os que se declararam amarelos e indígenas representaram 0,81\% e 0,14\% da população de proprietários, respectivamente, conforme se observa na Tabela 2.

Tabela 2_Proprietários segundo a raça ou cor - Brasil, 2003

\begin{tabular}{|c|c|c|}
\hline \multirow{2}{*}{ Raça } & \multicolumn{2}{|l|}{ Proprietários } \\
\hline & Freq. & $\%$ \\
\hline Indígena & 14.272 & 0,14 \\
\hline Branca & 5.566 .080 & 52,92 \\
\hline Preta & 616.796 & 5,86 \\
\hline Amarela & 85.041 & 0,81 \\
\hline Parda & 4.236.196 & 40,27 \\
\hline Total & 10.518 .385 & 100,00 \\
\hline
\end{tabular}

Fonte: Elaboração própria com base em dados extraídos da ECINF, 2003.

Gráfico 4_Proporção de proprietários segundo a faixa etária Brasil, 2003

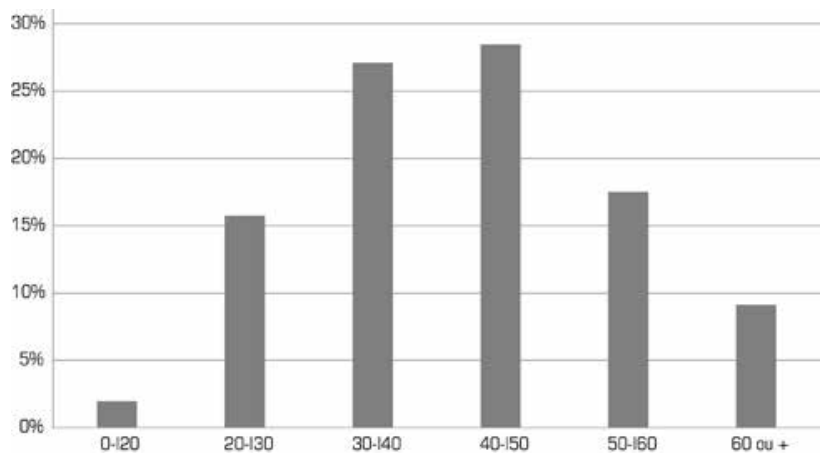

Fonte: Elaboração própria com base em dados extraídos da ECINF, 2003.
$\mathrm{Na}$ análise da distribuição dos proprietários segundo a faixa etária (Gráfico 4), verifica-se que $56 \%$ da população de proprietários analisados por faixa etária se concentrava principalmente na faixa dos 30 aos 50 anos de idade, enquanto $16 \%$ dessa população se concentrava na faixa dos 20 aos 30 anos, e $18 \%$, na faixa dos 50 aos 60 anos de idade.

De acordo com a amostra, é possível observar no Gráfico 5 que a maior parte da população de proprietários, segundo o nível de instrução, possuía o nível fundamental incompleto $(36 \%)$, ao passo que $20 \%$ dos proprietários tinham o ensino médio completo, e os que tinham ensino superior completo representavam $8 \%$ da população de proprietários que declararam seu nível de instrução. Analisando o nível de instrução separadamente para trabalhadores por conta própria e empregadores, percebe-se que, dentro de cada população, a proporção de trabalhadores e empregadores por nível de instrução varia. Dos empregadores, $25 \%$ tinham nível fundamental incompleto, enquanto $28 \%$ possuíam o nível médio completo. Já a proporção de empregadores que tinham o nível superior completo era de $18 \%$ da população de empregadores representada na amostra. Já os trabalhadores estavam concentrados principalmente no nível fundamental incompleto (39\%), 19\% possuíam nível médio completo, e 6\%, nível superior completo. Vale ressaltar ainda a relação apontada por Paulson e Townsend (2004) de que a educação pode servir como uma proxy de talento e habilidade gerencial dos empreendedores.

$\mathrm{O}$ acesso a instrumentos e serviços financeiros é um elemento importante da presente análise, uma vez que, por meio dos instrumentos e serviços financeiros e de outras características associadas à riqueza dos proprietários, será possível construir uma variável de riqueza para medir possíveis racionamentos de crédito. Ao se observar a população de proprietários selecionados na amostra, de acordo com o acesso a serviços e instrumentos financeiros, verifi- 


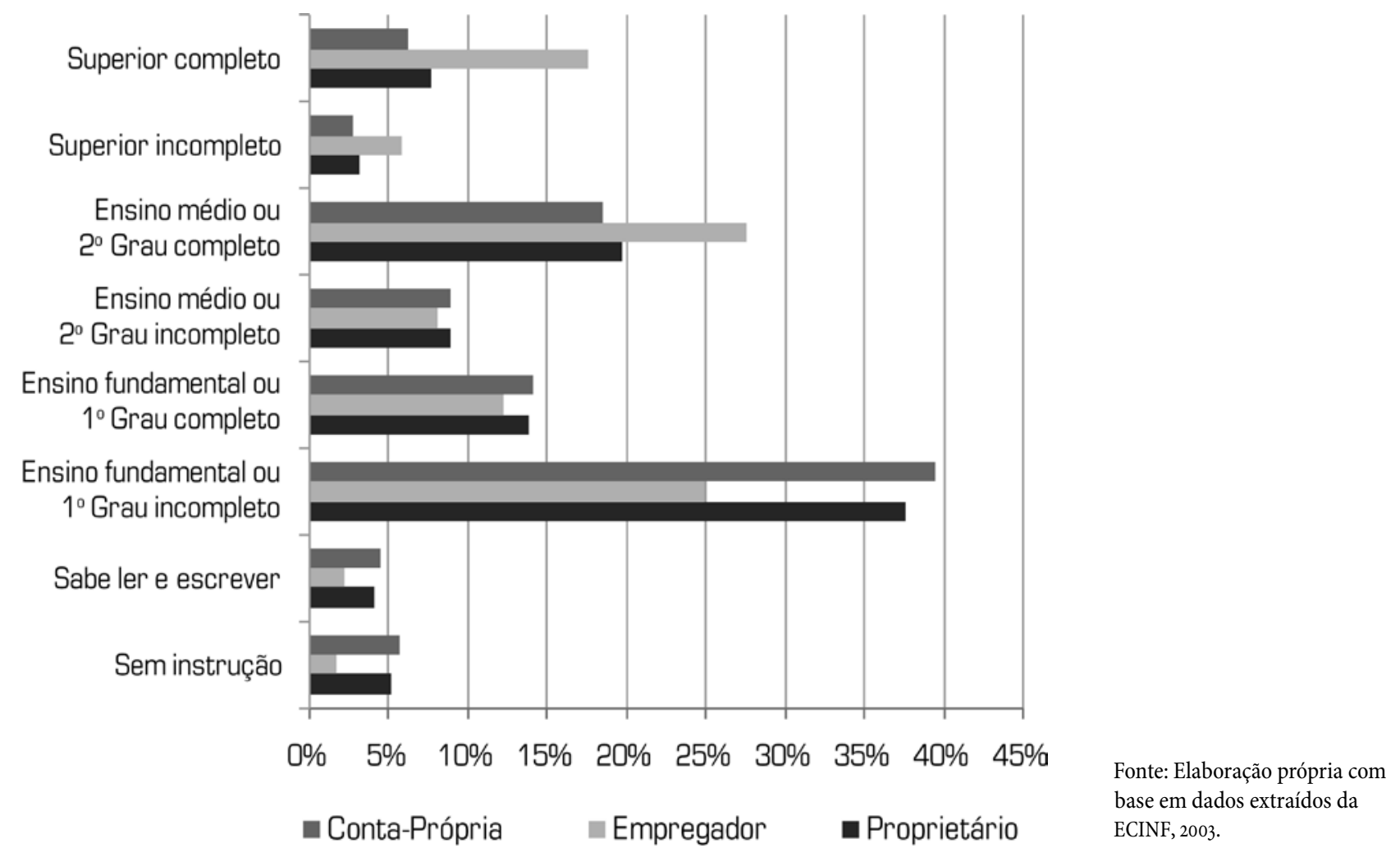

ca-se que $40 \%$ dos proprietários possuíam conta-corrente em algum banco, $32 \%$ desses proprietários tinham direito a talão de cheque e $22 \%$ tinham cheque especial (Gráfico 6). Já o percentual de proprietários que possuíam cartão de crédito era de $27 \%$, enquanto $24 \%$ possuíam caderneta de poupança e $22 \%$ tinham algum tipo de seguro. Analisando o acesso a instrumentos e serviços financeiros da população de proprietários que investiram, verifica-se que, da população selecionada na amostra, $48 \%$ possuíam conta-corrente, e, entre esses $48 \%$, os que tinham direito a talão de cheque correspondiam a $40 \%$ dos proprietários, enquanto os que tinham cheque especial representavam $31 \%$ da população selecionada na amostra. Os proprietários possuidores de cartão de crédito representavam $35 \%$ da população, enquanto os que tinham caderneta de poupança e seguro representavam $30 \%$ da amostra de proprietários com acesso a serviços e instrumentos financeiros.

Dos proprietários representados na amostra da ECINF, segundo a utilização ou não de equipamentos e/ou instalações (Tabela 3), $78 \%$ usavam equipamentos e/ou instalações próprios, e $71 \%$ dos proprietários empregavam algum tipo equipamento e/ou instalação próprios, ao passo que $7 \%$ 
Gráfico 6_Acesso a instrumentos e serviços financeiros Brasil, 2003

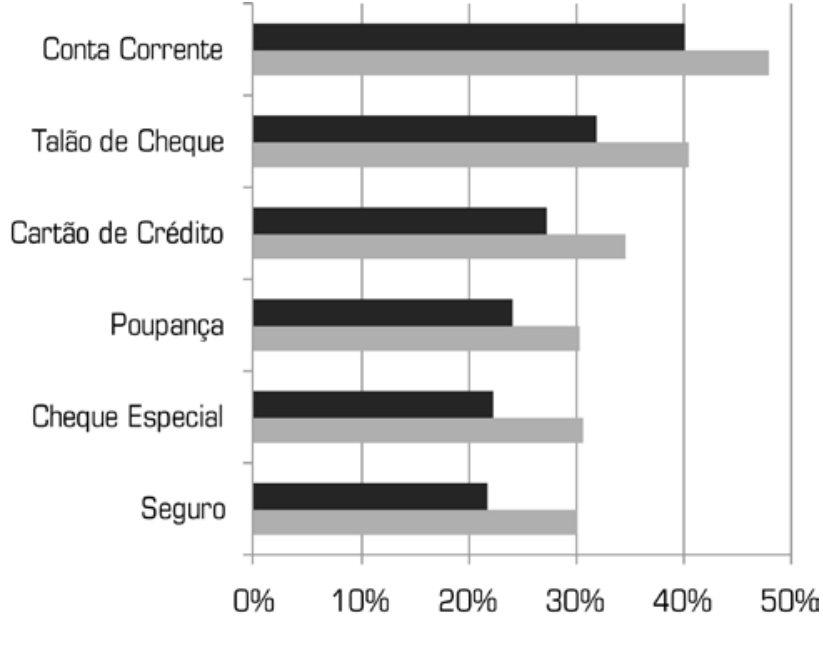

- Proprietários =

Fonte: Elaboração própria com base em dados extraídos da ECINF, 2003. dos proprietários usavam equipamentos e/ou instalações alugados ou cedidos. A importância dos proprietários que possuíam algum tipo de equipamento e/ou instalação se deve ao fato de que, quando for estimado por MQO, o modelo interessará apenas a esses proprietários, visto que, no questionário da ECINF, somente os proprietários que tinham algum equipamento e/ou instalação estavam aptos a responder à pergunta sobre a realização de investimento ou não nos 12 meses anteriores à pesquisa. Separando-se a população de proprietários em trabalhadores por conta própria e empregadores, verifica-se que, entre os trabalhadores contidos na amostra selecionada, $68 \%$ utilizavam equipamentos e/ou instalações, enquanto, entre a população de empregadores selecionados de acordo com o uso de equipamentos e/ou instalações, $91 \%$ utilizavam equipamentos e instalações de uso próprio.

Já, entre a população de proprietários que utilizavam equipamentos e/ou instalações próprios, $23 \%$ realizaram

Tabela 3_Utilização de equipamentos e/ou instalações - Brasil, nov./2003

\begin{tabular}{|c|c|c|c|c|c|c|}
\hline Usa equipamentos & Conta própria & & Empregadores & & Proprietários & \\
\hline e/ou instalações & Freq. & $\%$ & Freq. & $\%$ & Freq. & $\%$ \\
\hline Sim, próprio & 6.227.151 & 67,94 & 1.223.725 & 91,08 & 7.450 .876 & 70,90 \\
\hline $\begin{array}{l}\text { Sim, alugado } \\
\text { ou cedido }\end{array}$ & 688.582 & 7,51 & 80.087 & 5,96 & 768.669 & 7,31 \\
\hline Não & 2.249.951 & 24,55 & 39.751 & 2,96 & 2.289.702 & 21,79 \\
\hline Total & 9.165 .684 & 100,00 & 1.343 .563 & 100,00 & 10.509 .247 & 100,00 \\
\hline
\end{tabular}

Fonte: Elaboração própria com base em dados extraídos da ECINF, 2003.

Tabela 4_Investimentos e/ou aquisições realizados - Minas Gerais, 2003

\begin{tabular}{|c|c|c|c|c|c|c|}
\hline \multirow{2}{*}{$\begin{array}{l}\text { Fez algum investi- } \\
\text { mento ou aquisição? }\end{array}$} & \multicolumn{2}{|l|}{ Conta própria } & \multicolumn{2}{|l|}{ Empregadores } & \multicolumn{2}{|l|}{ Proprietários } \\
\hline & Freq. & $\%$ & Freq. & $\%$ & Freq. & $\%$ \\
\hline Sim & 1.254 .962 & $20,14 \%$ & 428.217 & $34,98 \%$ & 1.683 .179 & 22,57\% \\
\hline Não & 4.977 .490 & $79,86 \%$ & 79.609 & $65,02 \%$ & 5.773 .580 & $77,43 \%$ \\
\hline Total & 6.232.452 & $100,00 \%$ & 1.224 .307 & $100,00 \%$ & 7.456 .759 & $100,00 \%$ \\
\hline
\end{tabular}


algum investimento ou aquisição, mas, analisando-se a população de trabalhadores por conta própria, percebe-se que $20 \%$ da população de trabalhadores realizaram investimento, enquanto, dentro da população de empregadores, verifica-se que $35 \%$ dos empregadores representados na população realizaram investimento (Tabela 4 ).

\section{4_Proxy de riqueza}

A base de dados da ECINF não possui nenhum tipo de variável pela qual se possa mensurar diretamente a dotação dos indivíduos, mas, para uma análise de racionamento de crédito, é necessário definir uma medida de riqueza para, por meio dela, estabelecer uma relação com as decisões individuais dos proprietários. Para isso, a proxy de riqueza será construída tomando-se por base informações dos proprietários que estejam correlacionados com seu nível de dotação, tais como valor das instalações e equipamentos que são de propriedade desses proprietários e acesso a serviços financeiros.

Pela análise de componentes principais (ACP), é possível resumir as informações sobre riqueza contidas na base de dados da ECINF e, assim, obter unidades de medida (componentes principais) que sejam a combinação linear das variáveis utilizadas e que não apresentem correlação entre si, além de mostrarem máxima variabilidade entre os componentes gerados. A intenção é criar uma variável que consiga captar as variações de dotação entre os indivíduos da amostra selecionada e com base nela estabelecer uma relação entre riqueza e valor do investimento realizado. Pode-se perceber, por meio da Tabela 5 , que apresenta os autovalores do primeiro e do segundo componente principal, que o componente 1 explica $47 \%$ da variância contida no conjunto de dados, ao passo que o componente 2 é responsável por $14 \%$ da variância explicada.

O ideal na construção da proxy de riqueza seria que se utilizasse o máximo de características dos indivíduos
Tabela 5 _Análise de componentes principais primeiro componente principal

\begin{tabular}{|c|c|c|}
\hline Variáveis & Componente 1 & Componente 2 \\
\hline Valor de instalações e equipamentos & 0,1866 & 0,2971 \\
\hline Possui casa própria & 0,0276 & 0,9485 \\
\hline Possui conta-corrente & 0,4748 & $-0,0664$ \\
\hline Possui cheque especial & 0,4687 & $-0,0301$ \\
\hline Possui talão de cheque & 0,4940 & $-0,0494$ \\
\hline Possui cartão de crédito & 0,3861 & $-0,0584$ \\
\hline Possui seguro & 0,3552 & 0,0310 \\
\hline Variância explicada & $47,37 \%$ & $14,38 \%$ \\
\hline
\end{tabular}

Fonte: Elaborado com base nos dados extraídos da ECINF, 2003.

relativas à riqueza desses para que se reduzissem possíveis erros de medida. Mas, em razão de uma restrição na quantidade de informações acerca das variáveis correlacionadas com o nível de dotação dos indivíduos, pode acabar ocorrendo um viés na identificação dos proprietários segundo o nível de riqueza. E, mesmo que a variável de valor de instalações e equipamentos apresente boa variabilidade do nível de riqueza dos indivíduos, os mais ricos podem não estar totalmente representados de acordo com sua riqueza. Caso isso seja verdade, as decisões dos indivíduos e seu nível de riqueza apresentarão um viés tendendo a zero, o que significaria subestimação do coeficiente de riqueza, não representando um problema para a nossa análise.

\section{4_Análise dos resultados}

\section{1_Riqueza e investimento}

Antes de se realizar a análise empírica, é oportuno observar os proprietários da amostra de acordo com a riqueza. Apesar de o nível de riqueza não representar medida relevante 
em termos de magnitude, é importante o seu valor relativo para que possam ser estabelecidas comparações entre os proprietários e a população representada na amostra.

A utilização de dois componentes principais para descrever a riqueza individual se deve ao fato de que cada um dos componentes capta diferentes fatores correlacionados à riqueza dos indivíduos. $\mathrm{O}$ primeiro componente é o que apresenta maior variância e está mais correlacionado com fatores dos proprietários que indiquem um tipo de riqueza que possa servir como colateral e que lhes garanta acesso a serviços e instrumentos financeiros. Já o segundo componente principal apresenta menor variância, e sua importância está exatamente na sua relação com a riqueza em ativos reais dos proprietários. Pelo fato de os componentes 1 e 2 apresentarem correlação zero, não é possível realizar nenhuma comparação entre ambos, sendo necessária uma análise de riqueza para cada um deles (Tabela 6).

Analisando-se a riqueza média na Tabela 6 para os décimos de riqueza dos componentes 1 e 2, percebe-se que a riqueza média dos proprietários representada por meio do componente 1 apresenta tendência crescente a partir do $5^{\circ}$ décimo de riqueza, com elevação da riqueza média nos demais décimos de riqueza; há grande diferença entre a riqueza média expressa no último e a expressa no primeiro décimo de riqueza. Já através dos décimos de riqueza do componente 2, observa-se que há tendência crescente na riqueza média dos proprietários à medida que os décimos de riqueza aumentam; há também uma diferença entre o primeiro e o último décimo de riqueza. Lembrando que o nível de riqueza não é importante, que os componentes 1 e 2 não possuem nenhuma correlação e não é possível realizar inferências mediante a comparação entre eles.

Por meio do Gráfico 7, é possível ver a proporção da população de proprietários que investiram pelos décimos de riqueza criados através do componente 1 e do componente 2.
Tabela 6 _Riqueza média por decil de riqueza

\begin{tabular}{|c|c|c|}
\hline $\begin{array}{l}\text { Decis de } \\
\text { riqueza }\end{array}$ & $\begin{array}{l}\text { Riqueza média } \\
\text { Componente } 1\end{array}$ & Componente 2 \\
\hline 1 & 0,50 & 1,16 \\
\hline 2 & 0,58 & 1,36 \\
\hline 3 & 0,58 & 3,07 \\
\hline 4 & 0,58 & 3,30 \\
\hline 5 & 0,60 & 3,42 \\
\hline 6 & 1,33 & 3,56 \\
\hline 7 & 2,05 & 3,57 \\
\hline 8 & 3,34 & 3,57 \\
\hline 9 & 4,55 & 3,59 \\
\hline 10 & 5,56 & 3,93 \\
\hline
\end{tabular}

Fonte: Elaborado com base em dados extraídos da ECINF, 2003.

Analisando-se os décimos da riqueza dos proprietários para o componente 1, nota-se que a proporção de proprietários que investiram é maior no $10^{\circ}(17 \%)$ e no $9^{\circ}$ décimos $(13 \%)$, mas, no $5^{\circ}$ décimo, que ocupa posição intermediária, concentra-se também $13 \%$ da população de proprietários que investiram. Os cinco últimos décimos de riqueza gerados por meio do componente 1 concentram $60 \%$ da população de proprietários que investiram. Já nos décimos de riqueza gerados por intermédio do componente 1, em que há maior peso das variáveis que indicam maior posse de ativos reais dos proprietários, pode-se observar que o $9^{\circ}$ e $010^{\circ}$ décimos concentram as maiores proporções da população de proprietários que investiram, $14 \%$ e 16\%, respectivamente, contudo a concentração de proprietários nos últimos 5 décimos é de 50\%. Essa análise da proporção dos proprietários que investiram interessa na medida em que será estimado um modelo para medir o impacto das restrições de crédito sobre a decisão de investir dos proprietários. 
Gráfico 7_Proporção de proprietários que investiram por décimo de riqueza - Brasil, nov./2003

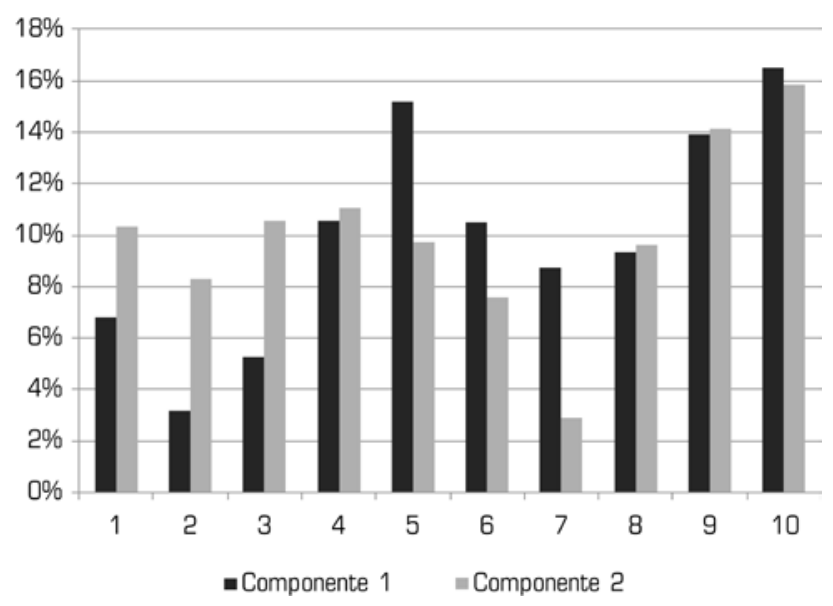

Fonte: Elaborado com base em dados extraídos da ECINF, 2003.

Tomando-se a média do logaritmo natural do valor do investimento, segundo os décimos de riqueza dos proprietários que realizaram algum investimento ou aquisição (Gráfico 8), percebe-se que, para os décimos de riqueza dos proprietários gerados através do componente 1 , a média do logaritmo não apresenta tendência de variação definida até $07^{\circ}$ décimo, a partir do qual a média do logaritmo se eleva progressivamente até o último décimo de riqueza. Por intermédio da média do logaritmo para os décimos de riqueza gerados por meio do componente 2, observa-se que essa segue tendência de crescimento definida a partir do $5^{\circ}$, não havendo grandes variações na média do logaritmo natural do valor do investimento. Através da estimação por MQO, deseja-se verificar possível relação linear entre o logaritmo natural do valor do investimento realizado pelos proprietários que investiram e a proxy de riqueza desses. Espera-se que, quanto maior for o valor do investimento, maior será o efeito da riqueza sobre esse, caso haja a existência de racionamento de crédito.
Gráfico 8_Média do logaritmo natural do valor do investimento por decil de riqueza dos proprietários que realizaram investimentos ou aquisições - Brasil, nov./2003

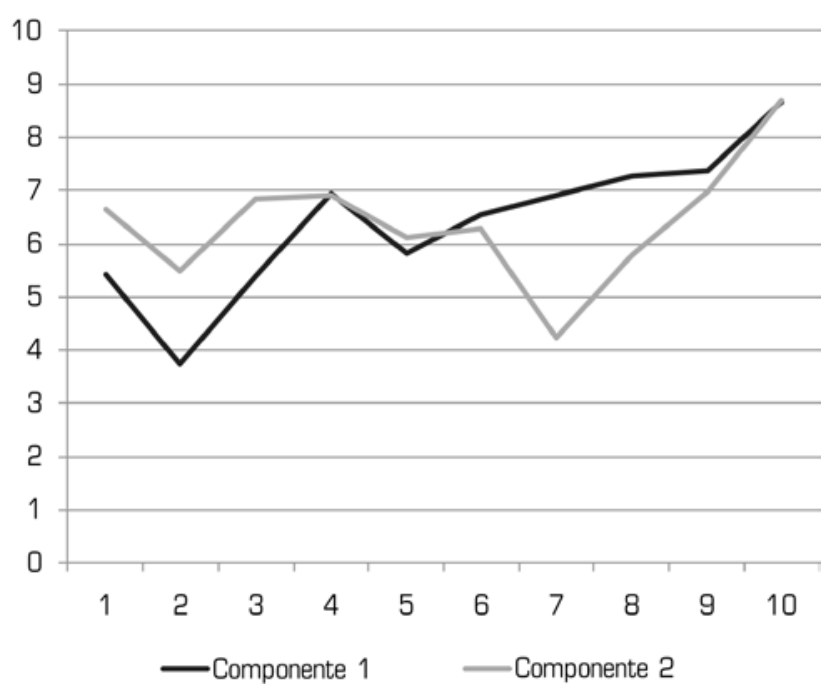

Fonte: Elaborado com base em dados extraídos da ECINF, 2003.

\section{2_Riqueza e decisão de investimento}

Conforme explicitado anteriormente na análise de componentes principais, por meio dos componentes 1 e 2, é possível resumir as informações sobre riqueza contida na base de dados da ECINF. O primeiro componente principal está altamente associado ao acesso a serviços e instrumentos financeiros dos proprietários do setor informal, ao passo que o segundo componente principal está altamente associado à riqueza em ativos reais dos proprietários.

Por intermédio do modelo probit, objetiva-se verificar a possível existência de restrições de crédito que afetem as decisões de investir dos proprietários do setor informal em áreas urbanas do Brasil. Se a hipótese de racionamento de crédito for correta, então, as decisões de investimento dos proprietários representados na amostra da ECINF estarão 
Tabela 7 Proprietários de negócios informais probabilidade de investir

\begin{tabular}{|c|c|c|c|c|}
\hline & 1 & 2 & 3 & 4 \\
\hline \multicolumn{5}{|l|}{ Riqueza } \\
\hline \multirow{2}{*}{$\begin{array}{l}\text { Acesso a serviços } \\
\text { financeiros }\end{array}$} & $0,075^{\text {前并并 }}$ & 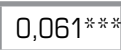 & $0,041^{\text {羊前并 }}$ & 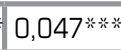 \\
\hline & $(0,008)$ & $(0,009)$ & $(0,009)$ & $(0,010)$ \\
\hline \multirow{2}{*}{ Ativos reais } & $-0,025 \%$ & 0,003 & 0,001 & 0,002 \\
\hline & $(0,014)$ & $(0,014)$ & $(0,014)$ & $(0,014)$ \\
\hline
\end{tabular}

\section{Características individuais}

\begin{tabular}{l|r|r|r|r}
\hline Idade & não & $\operatorname{sim}$ & $\operatorname{sim}$ & $\operatorname{sim}$ \\
\hline $\begin{array}{l}\text { Dummy de sexo } \\
\text { (homem=1) }\end{array}$ & não & $\operatorname{sim}$ & $\operatorname{sim}$ & $\operatorname{sim}$ \\
\hline Dummies de cor ou raça & não & $\operatorname{sim}$ & $\operatorname{sim}$ & $\operatorname{sim}$ \\
\hline $\begin{array}{l}\text { Dummies de nível } \\
\text { de instrução }\end{array}$ & não & $\operatorname{sim}$ & $\operatorname{sim}$ & $\operatorname{sim}$ \\
\hline
\end{tabular}

\section{Características do empreendimento}

\begin{tabular}{l|r|r|r|r}
\hline $\begin{array}{l}\text { Horas trabalhadas } \\
\text { no negócio }\end{array}$ & não & não & $\operatorname{sim}$ & $\operatorname{sim}$ \\
\hline $\begin{array}{l}\text { Pessoas ocupadas no } \\
\text { empreendimento }\end{array}$ & não & não & $\operatorname{sim}$ & $\operatorname{sim}$ \\
\hline $\begin{array}{l}\text { Dummy de empregador } \\
\begin{array}{l}\text { Dummies de grupo } \\
\text { de atividade }\end{array}\end{array}$ & não & não & $\operatorname{sim}$ & $\operatorname{sim}$ \\
\hline
\end{tabular}

\section{Indicador de formalização}

\begin{tabular}{l|r|r|r|r}
\hline Dummy de formalização & não & não & não & sim \\
\hline Dummies de Estado & $\operatorname{sim}$ & $\operatorname{sim}$ & $\operatorname{sim}$ & sim \\
\hline Constante & $-0,631$ & $-0,318$ & $-0,560$ & $-0,590$ \\
\hline Observações & 33791 & 33734 & 33682 & 33680 \\
\hline R2 ajustado & 0,018 & 0,041 & 0,058 & 0,059 \\
\hline * Significativo a 10\% ** Significativo a $5 \%$ & $* * *$ Significativo a 1\%
\end{tabular}

Fonte: Elaboração própria com base em informações da ECINF, 2003

sujeitas à riqueza inicial desses; sem acesso a crédito, resta aos proprietários utilizar os próprios recursos para investir.

Os resultados da estimação da probabilidade de os proprietários investirem podem ser vistos na Tabela 7. Foram realizadas quatro estimações, e, ao longo de cada estimação, foram acrescentadas variáveis de controle. Além das variáveis de riqueza, foram introduzidas: dummies para cada Es- tado da Federação, características dos proprietários, características do empreendimento e um indicador de formalização.

Os valores dos coeficientes de acesso a serviços financeiros e ativos reais, na Tabela 7 , representam os efeitos marginais da probabilidade de os proprietários de negócios informais em áreas urbanas do Brasil investirem de acordo com as variações no nível de riqueza desses.

Analisando-se os resultados das regressões, é possível perceber que os coeficientes da proxy de riqueza associada à forma de riqueza que garante acesso a serviços e instrumentos financeiros ao proprietário foram significativos a $1 \%$ em todas as regressões estimadas, enquanto a proxy de riqueza associada à riqueza em ativos reais dos proprietários foi significativa apenas na primeira regressão, mesmo assim seu coeficiente apresentou valor negativo, e, conforme foram incluídas as variáveis de controle, essa deixou de ser significante, apesar de se ter tornado positiva.

A interpretação dos resultados contidos nas regressões estimadas através do modelo probit indica a existência de racionamento de crédito ativo no setor informal em áreas urbanas do Brasil. As vias pela qual esse racionamento de crédito ocorre parecem ocorrer mediante o acesso dos proprietários a serviços e instrumentos financeiros, ou seja, pela importância da disponibilidade de colateral para se ter acesso ao crédito.

Os resultados demonstram que, quanto maior a riqueza dos proprietários vinculada à existência de colaterais e garantias que asseguram o seu acesso a serviços e instrumentos financeiros, maiores seriam a probabilidade de esse escolher investir, enquanto a riqueza dos proprietários vinculada à posse de ativos reais não demonstrou ser significativa na determinação da decisão de investir. Os proprietários que não dispõem de colaterais e garantias para oferecer e conseguir ter acesso a serviços e instrumentos financeiros enfrentam dificuldades na hora de investir; sem acesso ao 
mercado de crédito, esses podem acabar sendo impedidos de realizar investimentos ou de fazê-lo dentro do nível ótimo que assegura o maior retorno do investimento.

\section{3_Riqueza e valor do investimento}

Usando-se as variáveis de riqueza criadas, é possível também verificar a existência de restrições de crédito dentro do universo de proprietários que realizaram algum investimento ou aquisição nos 12 meses anteriores à pesquisa; tal relação foi medida via correlação entre a riqueza do proprietário e o valor do seu investimento, conforme os resultados apresentados na Tabela 8.

Do mesmo modo que, na seção anterior, foram estimadas quatro regressões, sendo adicionadas as mesmas variáveis de controle utilizadas na estimação do modelo probit. O interesse é verificar os possíveis impactos da riqueza dos proprietários sobre o valor do investimento que eles realizam; caso haja racionamento de crédito, então haverá forte correlação entre a riqueza individual e o valor do investimento realizado pelo proprietário.

Os resultados indicam relação entre ambas as proxies de riqueza e o valor do investimento. Tanto a variável de riqueza associada à existência de colateral por parte dos proprietários que lhes assegura o acesso a serviços e instrumentos financeiros quanto a variável de riqueza associada à riqueza em ativos reais dos proprietários demonstraram ser significativas em todas as regressões estimadas. À medida que se adicionaram variáveis de controle, houve atenuação dos efeitos da riqueza sobre o valor dos investimentos realizados pelos proprietários.

Os resultados demonstraram a existência de uma correlação entre ambas as variáveis de riqueza e o valor do investimento, considerando que essa correlação é positiva, de modo que os resultados evidenciam a existência de racionamento de crédito para os proprietários que investem.
Tabela 8 _Proprietários de negócios informais -

Valor do Investimento (In)

\begin{tabular}{|c|c|c|c|c|}
\hline & 1 & 2 & 3 & 4 \\
\hline \multicolumn{5}{|l|}{ Riqueza } \\
\hline \multirow{2}{*}{$\begin{array}{l}\text { Acesso a serviços } \\
\text { financeiros }\end{array}$} & $0,485^{* * * * *}$ & 0,379 前前 & 0,250 米关米 & $0,217^{\text {前前 }}$ \\
\hline & $(0,008)$ & $(0,009)$ & $(0,009)$ & $(0,010)$ \\
\hline \multirow{2}{*}{ Ativos reais } & 0,086 * * & $0,112^{* * * *}$ & $0,101^{* * * * * 4}$ & $0,093^{* * * * *}$ \\
\hline & $(0,014)$ & $(0,014)$ & $(0,014)$ & $(0,014)$ \\
\hline
\end{tabular}

\section{Características individuais}

\begin{tabular}{l|r|r|r|r}
\hline Idade & não & $\operatorname{sim}$ & $\operatorname{sim}$ & $\operatorname{sim}$ \\
\hline $\begin{array}{l}\text { Dummy de sexo } \\
\text { (homem=1) }\end{array}$ & não & $\operatorname{sim}$ & $\operatorname{sim}$ & $\operatorname{sim}$ \\
\hline Dummies de cor ou raça & não & $\operatorname{sim}$ & $\operatorname{sim}$ & $\operatorname{sim}$ \\
\hline $\begin{array}{l}\text { Dummies de nível de } \\
\text { instrução }\end{array}$ & não & $\operatorname{sim}$ & $\operatorname{sim}$ & $\operatorname{sim}$ \\
\hline
\end{tabular}

\section{Características do empreendimento}

\begin{tabular}{l|r|r|r|r}
\hline $\begin{array}{l}\text { Horas trabalhadas } \\
\text { no negócio }\end{array}$ & não & não & $\operatorname{sim}$ & $\operatorname{sim}$ \\
\hline $\begin{array}{l}\text { Pessoas ocupadas no } \\
\text { empreendimento }\end{array}$ & não & não & $\operatorname{sim}$ & $\operatorname{sim}$ \\
\hline $\begin{array}{l}\text { Dummy de empregador } \\
\begin{array}{l}\text { Dummies de grupo } \\
\text { de atividade }\end{array}\end{array}$ & não & não & $\operatorname{sim}$ & $\operatorname{sim}$ \\
\hline
\end{tabular}

\section{Indicador de formalização}

\begin{tabular}{|c|c|c|c|c|}
\hline Dummy de formalização & não & não & não & $\operatorname{sim}$ \\
\hline Dummies de Estado & $\operatorname{sim}$ & $\operatorname{sim}$ & $\operatorname{sim}$ & $\operatorname{sim}$ \\
\hline Observações & 7902 & 7889 & 7878 & 7874 \\
\hline $\mathrm{R} 2$ & 0,257 & 0,318 & 0,448 & 0,458 \\
\hline
\end{tabular}

* Significativo a $10 \% \quad{ }^{* *}$ Significativo a $5 \% \quad * * *$ Significativo a $1 \%$

Fonte: Elaboração própria com base em informações da ECINF, 2003

Quanto maiores são a existência de colateral e a riqueza em ativos reais do proprietário, maior tende a ser o montante investido por esse. Os proprietários que detêm menor posse de ativos reais e não dispõem de colaterais ou garantias que lhes permitam ter acesso a serviços e instrumentos financeiros estão restringidos no montante que podem investir. 


\section{5_Considerações finais}

O objetivo do presente trabalho é analisar o setor informal em áreas urbanas do Brasil e estabelecer se os proprietários de negócios informais contidos na amostra da ECINF poderiam estar sujeitos a situações de racionamento de crédito. As informações encontradas na ECINF buscam captar as características de funcionamento das unidades produtivas do setor informal da economia urbana brasileira que deixam de ser captadas ou são captadas apenas parcialmente pelas demais fontes estatísticas disponíveis.

A literatura econômica sobre o tema do racionamento de crédito chama a atenção para a presença de incerteza nos mercados de crédito. Diante da existência de informação assimétrica, o equilíbrio nos mercados de crédito pode não ser determinado simplesmente pela taxa de juros. Variações nas taxas de juros podem gerar problemas de seleção adversa e risco moral, fazendo com que os emprestadores prefiram simplesmente restringir o crédito, ao invés de elevá-las.

Considerando que os investimentos apresentam indivisibilidades, indivíduos restritos ao crédito podem simplesmente se ver impedidos de investir ou então não ser capazes de investir o montante necessário para que obtenham $o$ retorno ótimo, o que implica perda de produtividade e eficiência. Não havendo mecanismos diretos precisos de observação do acesso ao crédito, uma alternativa para a mensuração de possíveis racionamentos de crédito é mediante a relação entre decisões individuais e a dotação inicial dos indivíduos.É exatamente essa relação que é explorada aqui para verificar a existência de restrições de crédito no setor informal em áreas urbanas do Brasil.

A análise da base de dados da ECINF demonstra elevada presença de trabalhadores por conta própria entre os proprietários de negócios informais em comparação com a presença de empregadores na amostra. As atividades de comércio e reparação, construção civil e indústria de trans- formação e extrativa concentram a maior parte da população de proprietários analisada.É predominante também a presença dos homens dentro do setor informal em áreas urbanas, e a maioria dos proprietários se encontra na faixa dos 30 aos 50 anos de idade.

Em termos de nível educacional, verifica-se que a maior parte dos proprietários possui nível fundamental incompleto, o mesmo ocorrendo em relação à população de trabalhadores por conta própria. Mas os empregadores apresentam maior nível de instrução em comparação com os trabalhadores por conta própria, com os empregadores com nível médio completo representando a maior parcela da população de empregadores segundo o nível de instrução. Ao se observar os proprietários, de acordo com a declaração de cor ou raça, verifica-se que os proprietários da amostra que se declararam como brancos e pardos representavam mais de $90 \%$ da população de proprietários contida na amostra.

A proporção de proprietários que realizaram algum investimento ou aquisição nos 12 meses anteriores à pesquisa não representa nem um quinto da população total de proprietários contida na amostra, mas vale ressaltar que, quando se toma empregadores e trabalhadores conta-própria separados, constata-se que a proporção da população de empregadores que investiu no período é bem maior do que a proporção da população de conta-própria que realizou investimento. Quando se verifica o acesso dos proprietários a serviços e instrumentos financeiros, percebe-se que o acesso a esses é maior entre os proprietários que investiram, mas, mesmo assim, há grande parcela de proprietários que não têm acesso a serviços e instrumentos financeiros.

Os resultados dos modelos estimados indicam a existência de restrições de crédito ativas no setor informal em áreas urbanas do Brasil. No caso da decisão de investir, os resultados apontam para correlação positiva e significati- 
va com o componente de riqueza associado à existência de colateral. Já na decisão sobre o montante a ser investido, observa-se correlação positiva e significativa entre o montante investido tanto com a existência de colateral ou acesso a serviços financeiros como com a riqueza medida em termos de posse de ativos reais dos empreendedores.

Por fim, cabe enfatizar que os resultados aqui apresentados se constituem apenas em um primeiro exercício para compreensão do funcionamento do mercado de crédito no setor informal. 
AGHION, P.; BOLTON, P. A Theory of Trickle-down Growth and Development. The Review of Economics Studies, v. 64,

p. 151-172, 1997.

ASSUNÇÃO, Juliano; CHEIN, Flavia. Condições de crédito no Brasil rural. Revista de Economia e Sociologia Rural, v. 45 , p. 367-408, 2007.

ASSUNÇÃO, Juliano Junqueira; ALVES, Luciana Sampaio. Restrições de crédito e decisões intrafamiliares. Revista Brasileira de Economia, v. 61, p. 201.229, 2007.

\section{BANERJEE, A. Contracting} constraints, credit markets, and economic development. In: KREPS, D. Advances in economics and econometrics: Theory and applications. Eighth World Congress, Vol. 3.

Cambridge University Press, 2001.

BANERJEE, A. Inequality and investment. In: FERREIRA, F.; WALTON, M.; World Development Report, 2006. (Eds.). Washington DC: World Bank, 2006.

BANERJEE, A. V.; NEWMAN, A. F. Occupational choice and the process of development. Journal of Political Economy, v. 101, p. 274-298, 1993.
BESANKO, David; THAKOR, Anjan V. Competitive equilibrium in the credit market under asymmetric information. Journal of Economic Theory, Elsevier, v. 42, n. 1, p. 167-182, 1987.

BESANKO, David; THAKOR,

Anjan V. Collateral and rationing: Sorting equilibria in monopolistic and competitive credit markets. International Economic Review, v. 28, n. 3, p. 671-89, 1987b.

BESTER, Helmut. Screening vs. Rationing in Credit Markets with Imperfect Information. The American Economic Review, v. 75, n. 4, p. 850-855, 1985.

COELHO, C.; MELLO, J. M. P.; FUNCHAL, B. The Brazilian Payroll Lending Experiment. Texto para Discussão n. 573 Departamento de Economia PUC-Rio. 2010.

EVANS, David S.; JOVANOVIC, Boyan. An estimated model of entrepreneurial choice under liquidity constraints. Journal of Political Economy, Vol. 97, N. 4, p. $808-827,1989$.

GALOR, O.; ZEIRA, J.

Income distribution and macroeconomics. The Review of Economics Studies, v. 60, p. 35-52, 1993 .
INSTITUTO BRASILEIRO DE GEOGRAFIA E ESTÁTISTICA. ECINF 2003, Rio de Janeiro, 2005.

JACOBY, H. G. Borrowing constraints and progress through school: Evidence from Peru. Review of Economics and Statistics, v. 76, p. 151-160, 1994.

JAFFEE, D.; STIGLITZ, J. Credit rationing. In: FRIEDMAN, Benjamin M.; HAHN, Frank H. Orgs. Handbook of Monetary Economics. North-Holiand, V. 2, p. $838-888,1990$.

JAFFEE, D. M.; RUSSEL, T. Imperfect information, uncertainty and credit rationing. The Quarterly Journal of Economics, v. 90, n. 4, p. 651-666, 1976 .

PAULSON, Anna; TOWNSEND, Robert. Entrepreneurship and financial constraints in Thailand. Journal of Corporate Finance, v. 10, n. 2, p. 229-262, 2004.

RAJAN, R.; ZINGALES, L.

Financial dependence and growth. American Economic Review, v. 88, p. 559-586, 1998.

STIGLITZ, J. E.; WEISS, A. Credit rationing in markets with imperfect information. The American Economic Review, v. 71, n. 3, p. 393-410, 1981.
STIGLITZ, J.; WEISS, A. Credit rationing and collateral. In: EDWARDS, Jeremy et al. (Eds.). Recent developments in corporate finance. New York: Cambridge University Press, p. 101-135, 1986.
Os autores agradecem ao financiamento recebido pela Fundação de Amparo à Pesquisa de Minas Gerais (FAPEMIG), por meio do edital Primeiros Projetos/2008.

E-mail de contato dos autores: flavia.chein@ufjf.edu.br uirasilva@gmail.com

Artigo recebido em dezembro de 2011 e aprovado em julho de 2012. 